\title{
Síntese de Fotocatalisadores híbridos com Zn e Ti para aplicação na remoção de corantes residuais de efluentes da indústria têxtil
}

\section{Renan A. Schimitd ${ }^{*}$ Elias B. Tambourgi}

\section{Resumo}

Neste projeto foi abordada a síntese de fotocatalisadores de alumina dopados com porcentagens de $25 \%$ e $45 \%$ de zinco e titânio, empregados na degradação fotoquímica do corante $\mathrm{Cl}$ Reactive Blue - 21. Foram analisados os fenômenos de adsorção, fotocatálise e fotólise. Os resultados de adsorção indicaram que o modelo de monocamadas de Langmuir foi o mais adequado para ajustar os dados experimentais e, ao realizar um estudo cinético, o modelo de pseudo segunda ordem apresentou a maior correlação com os dados experimentais em relação aos modelos de pseudo primeira ordem e Elovich. Após realizar experimentos de fotocatálise, foi possível notar que a porcentagem de corante removida foi maior ao utilizar o catalisador alumina dopado com $25 \%$ de zinco em relação ao $\mathrm{ZnO} 99,99 \%$ Sigma-Aldrich 255750 - 106, fato confirmado pela análise da área BET.

\section{Palavras-chave:}

Fotocatálise, Indústria Têxtil e Corantes

\section{Introdução}

A necessidade de tratamento de resíduos de corantes oriundos da indústria têxtil, que não podem ser removidos por métodos convencionais, requer o desenvolvimento de tecnologias e alternativas de separação mais eficientes ${ }^{1}$. Desse modo, esse trabalho tem como objetivo analisar a degradação de corante $\mathrm{Cl}$ Reactive Blue 21 utilizando radiação ultravioleta e fotocatalisadores sintetizados em laboratório por meio de um processo sol-gel, determinando os parâmetros de adsorção e a porcentagem de degradação fotoquímica, por meio da avaliação individual dos efeitos de fotólise, fotocatálise e adsorção.

\section{Resultados e Discussão}

Utilizando um reator em batelada com duas lâmpadas ultravioleta e um agitador magnético, foram coletadas amostras em volumes definidos, as quais, após centrifugação, foram analisadas em um espectrofotômetro.

A análise de adsorção da y alumina demonstrou que, por meio da aplicação do método de regressão linear, o modelo de Langmuir ${ }^{2}$ foi mais preciso que os modelos de Temkin ${ }^{1}$ e Freundlich ${ }^{1}$.

O estudo cinético evidenciou que o modelo de pseudo segunda ordem era mais adequado do que pseudo primeira ordem e Elovich.

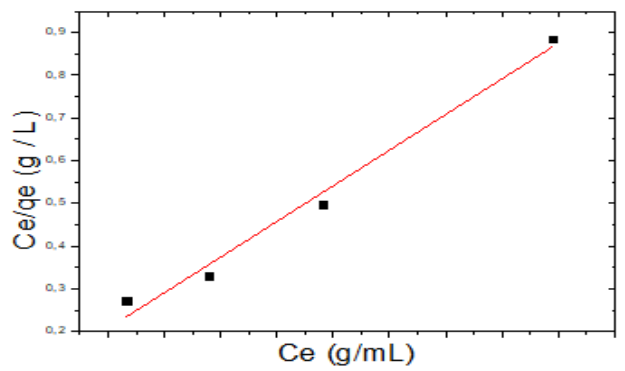

Figura 1. Isoterma de adsorção de corante de RB21 em y alumina utilizando o modelo de Langmuir

Os experimentos de fotocatálise e de adsorção foram realizados simultaneamente, com duração definida de $1 \mathrm{~h}$ e, ao final, a porcentagem de remoção de cor foi maior utilizando $\mathrm{Al}_{2} \mathrm{O}_{3} 25 \% \mathrm{Zn}$ e $\mathrm{ZnO}$ comercial 99,99\% Sigma Aldrich 255750 - 106. Experimentos posteriores apresentaram os resultados descritos na figura 2, evidenciando que o $\mathrm{ZnO}$ dopado com 25\% promoveu maior degradação, tanto por fotocatálise, quanto por adsorção. A justificativa para esse fato foi apresentada pela maior área superficial (tabela 1).

Tabela 1. Comparação da porcentagem de remoção de cor e da área superficial por fotocatalisador

\begin{tabular}{|c|c|c|c|}
\hline Catalisador & Adsorção & Fotocatálise & $\begin{array}{c}\text { Área BET } \\
\left(\mathrm{m}^{2} / \mathrm{g}\right)\end{array}$ \\
\hline $\mathrm{Al}_{2} \mathrm{O}_{3} 25 \% \mathrm{Zn}$ & 68,10 & 95,95 & 207,19 \\
\hline $\mathrm{Al}_{2} \mathrm{O}_{3} 45 \% \mathrm{Zn}$ & 42,38 & 67,34 & 87,44 \\
\hline $\mathrm{Al}_{2} \mathrm{O}_{3} 25 \% \mathrm{Ti}$ & 9,26 & 40,19 & 90,21 \\
\hline $\mathrm{Al}_{2} \mathrm{O}_{3} 45 \% \mathrm{Ti}$ & 12,71 & 24,77 & 94,77 \\
\hline
\end{tabular}

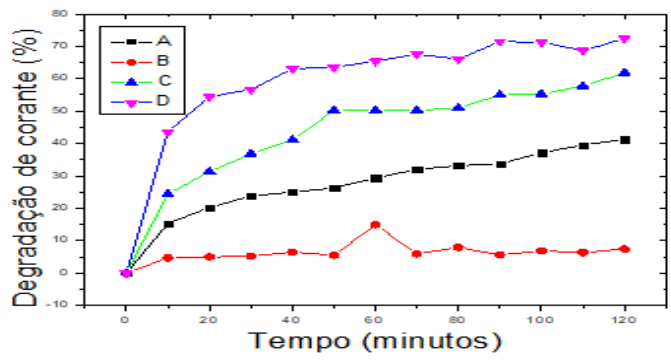
A - ZnO Fotocatálise
C $-25 \%$ Zn Adsorção
$\mathrm{B}-\mathrm{ZnO}$ Adsorção
D- $25 \%$ Zn Fotocatálise

Figura 2. Comparação entre os catalisadores mais eficientes e os respectivos efeitos

\section{Conclusões}

- Isoterma de adsorção de Langmuir e cinética de pseudo segunda ordem.

- O catalisador mais eficiente foi alumina dopada com $25 \%$ de Zinco.

\section{Agradecimentos}

Gostaria de agradecer ao PIBIC/SAE/UNICAMP e ao professor Elias Basile Tambourgi pela orientação.

\footnotetext{
${ }^{1}$ Vanaamudan, A.; Chavada, B.; Padmaja, P.; Journal of Environmental

Chemical Engineering, v. 4, p. 2617-2627, 2016

2 Aksu, Z., Process Biochemistry, v.38, p. 89-99. 2002
} 